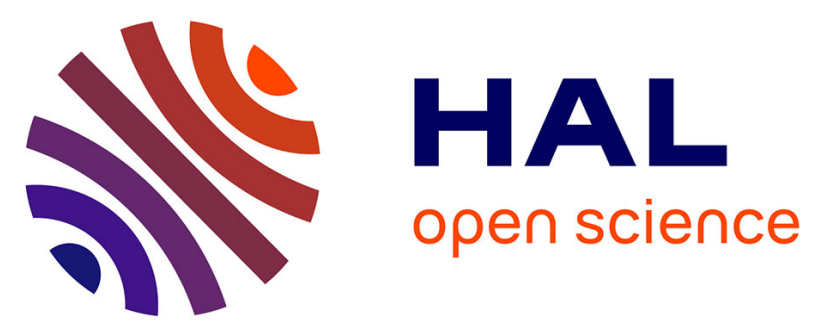

\title{
Impaired neurogenesis, neuronal loss, and brain functional deficits in the APPxPS1-Ki mouse model of Alzheimer's disease
}

\author{
Alexis Faure, Laure Verret, Bruno Bozon, Nadine El Tannir El Tayara, M. Ly, \\ F. Kober, Marc Dhenain, Claire Rampon, Benoit Delatour
}

\section{To cite this version:}

Alexis Faure, Laure Verret, Bruno Bozon, Nadine El Tannir El Tayara, M. Ly, et al.. Impaired neurogenesis, neuronal loss, and brain functional deficits in the APPxPS1-Ki mouse model of Alzheimer's disease. Neurobiology of Aging, 2011, 32 (3), pp.407-418. 10.1016/j.neurobiolaging.2009.03.009 . hal-02360495

\section{HAL Id: hal-02360495 \\ https://hal.science/hal-02360495}

Submitted on 25 May 2021

HAL is a multi-disciplinary open access archive for the deposit and dissemination of scientific research documents, whether they are published or not. The documents may come from teaching and research institutions in France or abroad, or from public or private research centers.
L'archive ouverte pluridisciplinaire HAL, est destinée au dépôt et à la diffusion de documents scientifiques de niveau recherche, publiés ou non, émanant des établissements d'enseignement et de recherche français ou étrangers, des laboratoires publics ou privés. 
Title: Impaired neurogenesis, neuronal loss, and brain functional deficits in the APPxPS1-Ki mouse model of Alzheimer's disease

Authors and author addresses: Faure, A. ${ }^{1}$, Verret, L. ${ }^{2,}{ }^{3}$, Bozon, B. ${ }^{1}$, El Tayara, N. ${ }^{4,5}$, Ly, M ${ }^{1}$., Kober, F. ${ }^{6}$, Dhenain, M. ${ }^{7,8,9}$, Rampon, C. ${ }^{2,3}$, Delatour, $\mathrm{B}^{1,}{ }^{*}$.

${ }^{1}$ CNRS, Lab NAMC, UMR8620, Université Paris Sud, 91405, Orsay, France.

${ }^{2}$ Université de Toulouse; UPS; Centre de Recherches sur la Cognition Animale; 118 route de Narbonne, F31062 Toulouse Cedex 9, France

${ }^{3}$ CNRS; Centre de Recherches sur la Cognition Animale; F-31062 Toulouse, France

${ }^{4}$ INSERM, U759, Centre Universitaire. Laboratoire 112, 91405 Orsay Cedex, France.

${ }^{5}$ Institut Curie, Centre Universitaire. Laboratoire 112, Orsay 91405, France.

${ }^{6}$ Centre de Résonance Magnétique Biologique et Médicale (CRMBM), UMR CNRS 6612, Faculté de Médecine, Université de la Méditerranée, Marseille, France

${ }^{7}$ CEA, DSV, I²BM, SHFJ, MIRCen Program, 4 Place du Général Leclerc, 91401 Orsay Cedex, France.

${ }^{8}$ CNRS, URA 2210, 4 Place du Général Leclerc, 91401 Orsay Cedex, France.

${ }^{9}$ CEA, DSV, I2BM, NeuroSpin, Centre CEA de Saclay, Bât. 145, 91191 Gif sur Yvette, France

Authors'e-mail adresses: A. Faure: alexis.faure@u-psud.fr; L. Verret: verret@cict.fr; B. Bozon: bruno.bozon@upsud.fr; N. El Tayara: Nadine.El-Tayara@curie.u-psud.fr; F. Kober: frank.kober@univmed.fr; M. Dhenain: Marc.Dhenain@cea.fr; C. Rampon: rampon@cict.fr; B. Delatour: benoit.delatour@u-psud.fr

* Corresponding author. Tel : 33-1 691549 88; Fax: 33-1 6915 77 26; e-mail : benoit.delatour@u-psud.fr 


\begin{abstract}
Amyloid- $\beta$ peptide species accumulating in the brain of patients with Alzheimer's disease are assumed to have a neurotoxic action and hence to be key actors in the physiopathology of this neurodegenerative disease. We have studied a new mouse mutant (APPxPS1-Ki) line developing both early-onset brain amyloid- $\beta$ deposition and, in contrast to most of transgenic models, subsequent neuronal loss. In six-month old mice, we observed cell layer atrophies in the hippocampus, together with a dramatic decrease in neurogenesis and a reduced brain blood perfusion as measured in vivo by magnetic resonance imaging. In these mice, neurological impairments and spatial hippocampal dependant memory deficits were also substantiated and worsened with aging. We described here a phenotype of APPxPS1-Ki mice that summarizes several neuroanatomical alterations and functional deficits evocative of the human pathology. Such a transgenic model that displays strong face validity might be highly beneficial to future research on AD physiopathogeny and therapeutics.
\end{abstract}

Keywords: alzheimer's disease; amyloid- $\beta$ peptide; hippocampus; neurogenesis; learning and memory; brain blood perfusion 


\section{Introduction}

Alzheimer's disease $(\mathrm{AD})$ is a progressive neurodegenerative disorder which accounts for the majority of dementia cases in the elderly population. The neuropathological hallmarks of AD include extracellular amyloid- $\beta$ (A $\beta$ ) deposition, intracellular tau accumulation, neuronal and synaptic losses. Because familial AD is associated with mutations of the amyloid protein precursor (APP) or presenilin (PS) genes, many mouse lines that overexpress human transgenes bearing these mutations have been generated over the two last decades. Whereas most of these transgenic mice develop amyloid deposits, the majority of them fail to exhibit significant neuronal loss. In the few mouse lines showing altered neuronal densities, cell loss remains weak or limited to the vicinity of amyloid deposits and does not reflect the drastic neuronal reduction observed in AD patients (Calhoun et al., 1998, Irizarry et al., 1997, Takeuchi et al., 2000, Urbanc et al., 2002). These observations challenge the cascade hypothesis that posits $A \beta$ accretion as a primary neurotoxic event triggering morphological and functional brain anomalies, ultimately leading to neuronal death and dementia (Hardy and Higgins, 1992).

It is only recently that mouse lines harboring multiple mutated APP and PS1 transgenes and developing aggressive and early-onset brain amyloidosis, have been reported to undergo brain atrophies and substantial cell loss (e.g. Oakley et al., 2006, Schmitz et al., 2004). In one of these models, the APPxPS1-knock-in line (Casas et al., 2004), a severe hippocampal cell loss (50\%) has been reported at the age of 10 months. It mimics both the topography and extent of the neuronal loss observed in the hippocampus of AD patients (Scher et al., 2007, West et al., 2000). At the behavioral level, working memory deficits have been described in APPxPS1-Ki mice (Bayer and Wirths, 2008, Wirths et al., 2007), but it remains unknown whether these mice also develop medial temporal lobe dysfunction, and particularly hippocampus-dependent learning impairments, as has been reported for human patients.

In the present study we used a multi-disciplinary approach to characterize in detail the APP/PS-Ki mouse phenotype. We evaluated the nature and extent of $A \beta$-associated morphological anomalies and the occurrence of neurological and cognitive impairments in this mouse model. Because adult neurogenesis may provide a means for neuronal replacement in the AD brain, we also examined whether the progressive neuronal loss displayed by APP/PS1-Ki is associated with modified hippocampal neurogenic processes. Finally, to substantiate brain 
dysfunction in APPxPS1-Ki mice, we performed blood perfusion analysis by means of in vivo magnetic resonance imaging (MRI) techniques.

\section{Material and methods}

\subsection{Animals}

Transgenic mice were established as previously described (Casas et al., 2004). In short, mice were generated by crossing homozygous PS1-Ki (carrying presenilin 1 knock-in M233T and L235P mutations) with hemizygous $\mathrm{APP}_{\mathrm{SL}}$ mice $\left(\mathrm{hAPP}_{751}\right.$ transgene with the Swedish K670N/M671L and London V717I mutations, under the control of a Thy1 promoter) to obtain APPxPS1-Ki transgenics harboring in total 5 mutations associated with familial $\mathrm{AD}$ on a mixed genetic background (C57BL/6 50\% - CBA 25\% - 129SV 25\%). Note that, owing to the use of homozygous PS1-Ki mice, no wild-type littermates could be generated from the breeding scheme. However the PS1-Ki mice are free of neuropathological lesions (amyloid deposits, neuronal loss or axonopathy) and have been considered in previous studies to be good littermate controls for APPxPS1-Ki mice (Wirths et al., 2007, Wirths et al., 2006).

Mice were 6 weeks old at their arrival in the laboratory. They were acclimated during at least two weeks to their new environment before initiating experiments.. A total of 60 PS1-Ki and 57 APPxPS1-Ki male mice were used. All experiments were conducted in accordance with the ethical standards of French and European laws (European Communities Council Directive of 24 November 1986). The supervisor of the present study (B. Delatour) had received official agreements from the French Ministry of Agriculture to carry out research and experiments on animals (authorization No. 91-282). Experiments were performed in compliance and following approval of the Sanofi-Aventis Animal Care and Use Committee. The general health of mice was regularly checked and body weights were assessed weekly throughout the experimental period.

\subsection{Histology and biochemistry}

Mice (PS1-Ki, n= 30; APPXPS1-Ki, n= 28) were sacrificed at the age of 6 months with an overdose of sodium pentobarbital and were perfused transcardially with saline solution. After removal, the brains were weighed and 
photographed. From macro-photographs, the brain length was measured at the midline level using the measure tool of Photoshop CS2 (Adobe, Paris, France).

Left hemispheres were snap-frozen in liquid nitrogen and stored at $-80^{\circ} \mathrm{C}$. The $\mathrm{A} \beta$ peptides biochemical load $(\mathrm{A} \beta$ 42 and total $\mathrm{A} \beta$ ) was determined by electrochemiluminescence assays as previously described (Blanchard et al., 2003).

Right hemispheres were sectioned (frontal $40 \mu \mathrm{m}$-thick sections) on a freezing microtome after one-week fixation in $10 \%$ formalin and subsequent cryoprotection.

Hippocampal tissue loss was evaluated after Nissl (thionin) stain by measuring the pyramidal cell layer thickness. Although biased, this method allows rapid evaluation of local morphological changes. From previous studies, it has been shown that aged APPxPS1-Ki mice display progressive layer thinning in close association with neuronal loss (Casas et al., 2004). All slides were digitized using a Super CoolScan 8000 ED scanner (Nikon, Champigny sur Marne, France) with a 4000 dpi in-plane digitization resolution (pixel size $6.35 \mu \mathrm{m}^{2}$ ). Sections at the level of the dorsal hippocampi ( $n=3-4$ sections / mouse) were selected and the CA1-2 region manually delineated with Photoshop CS2. For each section, the thickness of the pyramidal cell layer was measured at 3 medio-lateral levels so that a total of 9-12 measures were performed and averaged for every mouse. Amyloid deposits were labeled by standard Congo red staining (30 min in a $80 \%$ ethanol solution saturated with Congo red and sodium chloride). Amyloid loads were quantified using computer-based thresholding methods as previously implemented (Le Cudennec et al., 2008). Evaluation of amyloid loads was performed in multiple regions of interest (ROIs): the total hippocampus, the dorsal (septal) hippocampus, the whole cortex (i.e. isocortex plus hippocampus), and the prefrontal cortex. Quantitative analyses were made on several serial sections to sample the whole rostro-caudal extent of each ROI.

Evaluation of neurogenic activity and cell differentiation was performed using antibodies directed against Ki67 (a proliferation marker) or against doublecortin (DCX, a marker of neuronal precursors). Immunolabelings were performed in a subset of the neuropathologically-assessed population (for Ki67: 6 PS1-Ki and 5 APPxPS1-Ki mice; for DCX: 15 PS1-Ki and 14 APPxPS1-Ki mice) using classical immunoperoxidase methods (Verret et al., 2007). Ki67 was detected using a primary rabbit anti-human Ki67 antibody (NCL-Ki67p, Novocastra Laboratories / Vision BioSystems, Newcastle Upon Tyne, UK; 1:500 overnight at room temperature) while DCX 
immunolabeling was performed with a polyclonal goat anti-DCX antibody (C-18, Santa Cruz, Santa Cruz, CA, USA; 1:100 overnight at room temperature). Final reactions made use of diaminobenzidine or nickel-enhanced diaminobenzidine as chromogens. The number of Ki67 and DCX-immunostained cells (Ki67+ or DCX+) was evaluated from peroxidase-labeled sections spaced at $480 \mu \mathrm{m}$ and spanning the whole septo-temporal extent of the hippocampus.

Cell countings and measurement of surfaces areas of dentate gyrus were performed using the Mercator stereology system (Explora Nova, La Rochelle, France) as previously described (Verret et al., 2007).

\subsection{MRI-assessed brain perfusion}

Fourteen PS1-Ki and 14 APPxPS1-Ki mice received MRI perfusion assessment before sacrifice and neuropathological examination (see above). Cerebral blood flow (CBF) was evaluated by using a pulsed arterial spin labeling technique. The animals were anesthetized with isoflurane ( $4 \%$ for induction, $1-1.5 \%$ for maintenance) in a mixture of $\mathrm{N}_{2}(80 \%)$ and $\mathrm{O}_{2}(20 \%)$ administered via a facemask. Respiration rate was monitored to insure stable physiologic conditions during the acquisitions. The body temperature of the mice was stabilized by using a heating blanket.

In vivo MR images were recorded on a 4.7 Tesla Bruker Biospec 47/30 system equipped with a $12 \mathrm{~cm}$ diameter gradient system $(200 \mathrm{mT} / \mathrm{m})$. A surface coil (diameter=25 mm), actively decoupled from the transmitting birdcage probe (Bruker $\mathrm{GmbH}$ ) was used for signal acquisition. Perfusion measurements were performed using a FAIR Look-Locker gradient-echo method described elsewhere (Kober et al., 2008). Briefly, a series of 50 echoes was acquired after global or slice-selective magnetization inversion with the following imaging parameters: $\mathrm{TE} / \mathrm{TR}=1.59 / 150 \mathrm{~ms}, \alpha=12.5^{\circ}$, FOV: 20x20 $\mathrm{mm}^{2}$, slice thickness: $1.5 \mathrm{~mm}$, input matrix: $128 \mathrm{x} 64$; total acquisition time $32 \mathrm{~min}$. Data acquisition was performed in a tissue slab of the posterior cerebrum (volume acquisition: from Bregma -1.82 to Bregma -3.28 according to Paxinos and Franklin, 2001). The thickness of this sampling slice was too large to measure perfusion in convoluted regions of interest (ROI) such as the hippocampus. Because of these methodological limits we evaluated perfusion in large ROIs with minimal shape variations across the antero-posterior axis of the studied slice. Two ROIs were selected: the posterior cortex and the thalamus. In these selected ROIs, perfusion values $(\mathrm{P})$, given in $\mathrm{ml} \cdot \mathrm{g}^{-1} \cdot \mathrm{min}^{-1}$, were calculated as follows: $\mathrm{P} / \lambda=$ 
$\left[\left(\mathrm{T} 1^{\text {global }} / \mathrm{T} 1^{\text {blood }}\right) *\left(1 / \mathrm{T} 1^{\text {selective }}-1 / \mathrm{T} 1^{\text {global }}\right)\right]($ program developed in an IDL environment (RSI, Boulder, CO, USA)). $\mathrm{T} 1^{\text {global }}$ was calculated from images recorded with a global inversion pulse while $\mathrm{T} 1^{\text {selective }}$ was calculated with the selective inversion pulse. The blood/tissue partition coefficient for water $(\lambda)$ was assumed to be $0.9 \mathrm{ml} / \mathrm{g}$ (Sun et al., 2004), and T1blood was 1.7s (Williams et al., 1992).

\subsection{Behavior}

Behavioral studies were carried out in 2 additional cohorts that were evaluated longitudinally at 2, 4 and 6 months of age. Neurological assessment was performed on 15 PS1-Ki and 14 APPxPS1-Ki mice. Another cohort was used to evaluate learning and memory functions (PS1-Ki, $n=15$; APPxPS1-Ki, $n=15 ; 2$ PS1-Ki and 1 APPxPS1-Ki mice died before the completion of the study and received only partial behavioral assessment).

\subsubsection{Neurological assessment}

A primary screen, derived from the SHIRPA test battery (Burguiere et al., 2005, Rogers et al., 1997), was performed to evaluate the general appearance of animals, spontaneous activity (e.g. jumping, freezing, rearing) and neurological reflexes. On the following days secondary/tertiary screens were performed as followed: 1- Motor strength was measured with the wire grid test. Strength suspension (four paws) was assessed on a grid. The mouse was placed on the center of the grid that was slowly turned upside down at a $20 \mathrm{~cm}$-height above the floor. Latency to fall was recorded (cut off: $1 \mathrm{~min}$ ).

2- Locomotor activity was measured in a squared open field (50x50 cm; luminosity: 35 Lux) with black walls 30 $\mathrm{cm}$ high. Each animal was placed in the center of the arena and allowed to freely explore it for $10 \mathrm{~min}$. Horizontal activity was monitored using the Any-Maze software (Stoelting, Wood Dale, USA). Time spent in the 10-cm wide peripheral zone and in the complementary $30 \times 30 \mathrm{~cm}$ central zone was recorded, and the number of rearings (vertical activity) was scored.

3- Locomotion was also assessed by monitoring mice during a 24-h period. Mice were moved to the experimental room and placed in a cage $(50 \times 15 \mathrm{~cm})$ with food and water available. Mice were observed during both light and dark phases with a CCTV camera (WV-BP312E, Panasonic, Saint Denis La Plaine, France) equipped with an infra-red lamp. Tracking was performed using Any-Maze software that recorded horizontal activity across the $24-\mathrm{h}$ period. 
4- Anxiety was evaluated in an elevated plus-maze (length, $28 \mathrm{~cm}$; width, $5 \mathrm{~cm}$; walls height, $16 \mathrm{~cm}$; height from floor: $40 \mathrm{~cm}$; overall luminosity in open arms: 70 Lux). Mice were placed in the central region of the maze and the locomotor activity and time spent in each arm were measured for a 5-min period using Any-Maze software.

\subsubsection{Cognitive evaluation}

Spatial memory was evaluated using the standard Morris water maze task. The maze was a $150-\mathrm{cm}$ diameter pool filled with opacified water $\left(21-22^{\circ} \mathrm{C}\right)$. A $10 \mathrm{~cm}$ diameter platform was submerged $0.5 \mathrm{~cm}$ below water surface in the center of one of the pool quadrants. The non-visible platform remained at constant position across trials but was varied at each age time points to promote new spatial learning in 2, 4 and 6-month old mice.

Training consisted in 5 consecutive daily sessions (6 trials / sessions; start positions pseudo-randomly varied from the four cardinal points). Each trial ended when the animal reached the platform. A 60-s cut off was used, after which the mouse was manually guided to the platform. Once on the platform animals were given a 30-s rest before being replaced in their cage. The inter-trial interval was approximately one hour. On the $5^{\text {th }}$ training session, a probe trial was performed after the last trial. During this memory retention test, the platform was removed and mice allowed to navigate for 60-s. Data were collected, analyzed and stored using Any-Maze software.

\subsection{Statistical analyses}

Morphological and perfusion data were analyzed with Student $t$-tests and Pearson coefficients of correlation using Statistica v6 (StatSoft, Inc., Tulsa, OK, USA) or Systat v11.0 (Systat Software Inc., Richmond, CA, USA) software packages. Behavioral data were analyzed mainly with two-factor analyses of variance (ANOVA) with repeated measures (with genotype as the between-subjects factor and age as the within-subjects factor), using Statistica v6 software. In order to facilitate the presentation of the results, the ANOVA statistics have been presented only by providing $p$-values when significant. 


\section{Results}

\subsection{Gross brain morphology and amyloid deposition in APPXPS1-Ki mice}

Brain lengths/widths were not different in the two genotypes $(t \mathrm{~s}(56)<1.08 ; p \mathrm{~s}>0.28)$. However, brain weights decreased significantly in 6-month old APPxPS1-Ki mice compared to PS1-Ki controls (mean $\pm \mathrm{SEM}=464 \pm 3.1$ mg for APPxPS1-Ki mice vs $490 \pm 4.7 \mathrm{mg}$ for PS1-Ki controls; $\mathrm{t}(56)=4.96 ; \mathrm{p}<0.0001)$.

Additional neuropathological analyses revealed in APPxPS1-Ki mice the presence of numerous extracellular, aggregated (Congo red positive) $\mathrm{A} \beta$ deposits in several brain regions including the hippocampus, almost all isocortical areas, and a subset of subcortical regions such as septal, thalamic and some brainstem nuclei (Fig. 1A, B, E). Congo red positive blood vessels were scant (0-3 vessels / section, almost exclusively located in thalamic regions and/or at the level of leptomeninges) indicating very limited cerebral amyloid angiopathy in APPxPS1-Ki mice.

We concurrently quantified $A \beta 42$ peptides by electrochemiluminescence assays in crude hemibrain homogenates. We found very high A $\beta 42$ concentration in APPxPS1-Ki mice (mean $\pm \mathrm{SEM}=79.9 \pm 4.3 \mu \mathrm{g} / \mathrm{g}$ tissue). Supporting our data, the prevalence of the A $\beta 42$ isoform has previously been reported in this transgenic line (Casas et al., 2004).

\subsection{Hippocampal cell loss and abolition of neurogenic activity in APPxPS1-Ki mice}

A remarkable thinning of the CA1-2 cell layer of the hippocampus was observed in 6-month old APPxP1-Ki mice. The thickness of the stratum pyramidale was $20 \%$ smaller in APPXPS1Ki mice in comparison with PS1-Ki animals (difference between genotypes: $\mathrm{t}(56)=11.16$; $\mathrm{p}<.0001$; Fig. $1 \mathrm{C}, \mathrm{D}, \mathrm{F}$ ).

The dentate gyrus volume was not different in PS1-Ki and APPxPS1-Ki mice (data not shown), as expected from previous studies (Casas et al., 2004, Cotel et al., 2008). However stereological analysis revealed a significant decrease in the number of mitotic, Ki67-immunoreactive, cells in dentate gyrus of APP/PS1-Ki mice $($ mean $\pm \mathrm{SEM}=285.7 \pm 40.8)$ compared to PS1-Ki animals $(462.1 \pm 48.1 ; t(9)=2.82 ; p<0.025 ;$ Fig. 2 A, B). To further address the fate of newborn cells in the dentate gyrus, we determined the number of cells that differentiated into neurons by quantifying the population of immature neuronal precursors expressing DCX. The 
number of DCX-positive cells was dramatically reduced in the dentate gyrus of APPxPS1-Ki mice (difference between genotypes: $t(27)=15.1 ; p<0.001$, Fig. $2 \mathrm{C}, \mathrm{D}, \mathrm{E})$. While we found that numbers of mitotic cells $(\mathrm{Ki67}+)$ and numbers of young immature neurons $(\mathrm{DCX}+)$ were positively correlated in PS1-Ki control mice $(\mathrm{r}=0.93$; $\mathrm{p}<.025)$, no correlation between those measures was found in APPxPS1-Ki mice ( $r=0.06$; ns). This suggests that the loss of DCX+ cells in APPxPS1-Ki mice may result only partly from altered proliferation of multipotent progenitor cells. Indeed, it is likely that the disappearance of neuronal precursors early during their maturation contribute to the dramatic loss of young immature DCX+ neurons. However, we cannot completely rule out the possibility that the loss of DCX+ cells concurrently reflects an increased glial destiny of newborn cells and/or their accelerated neuronal maturation, thereby shortening the time-window of DCX expression.

We did not find any significant correlations between hippocampal amyloid loads, measures of CA1-2 atrophy and quantitation of neurogenesis-associated markers Ki67 and DCX $(\mathrm{rs}<0.38 ; \mathrm{ps}>.17)$. This indicates that the various anatomo-pathological alterations found in the hippocampus of 6-month old APPxPS1-Ki mice, while possibly resulting from a common source, are not closely interdependent.

\subsection{Cortical hypoperfusion in APPXPS1-Ki mice}

To further investigate cerebral abnormalities in APPxPS1-Ki mice, and to address functional consequences of these alterations, we carried out brain perfusion analyses. We used MRI-based spin-labeling perfusion techniques in anaesthetized mice. Our results revealed a posterior cortical hypoperfusion in APPXPS1-Ki as compared to PS1-Ki mice $(t(26)=2.38 ; p<.025$; Fig. $2 \mathrm{~F})$ while levels of subcortical (thalamic) perfusion were not different between genotypes $(t(26)=1.40 ; \mathrm{ns} ;$ mean $\pm \mathrm{SEM}=3.7 \pm 0.1$ and 3.5 \pm 0.1 inAPPxPS1-Ki and PS1-Ki, respectively), underlining the finding that blood flow impairments in APPxPS1-Ki remained restricted to selected brain areas.

\subsection{Early-onset neurological impairments in APPXPS1-Ki mice}

\subsubsection{Reduced vertical activity and motor strength}

Basic neurological evaluation revealed alterations of vertical activity (number of rearings) in APPxPS1-Ki mice (Table 1a): ANOVA indicated a significant effect of Genotype $(p<.001)$ and Age $(p<.005)$ as well as an Age $\mathrm{x}$ 
Genotype interaction $(p<.005)$. In comparison to PS1 control mice, APPxPS1-Ki mice presented reduced vertical activity at 4 and 6 months of age. There were no differences between genotypes on the other measurements provided during basic neurological evaluation (i.e. reflexes, spontaneous behaviors, etc.).

The wire grid test revealed significant effects of Genotype, Age and an interaction between the two factors (all $p s<.001)$. A large reduction of motor strength was hence detected in APPxPS1-Ki transgenic as compared to PS1-Ki mice at 4 and 6 months of age (Table 1b).

\subsubsection{Increased locomotor activity}

Hyperactivity was observed in APPxPS1-Ki mice when evaluated during the 24-h actimetry test (Fig. 3). An effect of the Genotype factor was noted $(p<.005)$ and the effect of Age and the Age $\mathrm{x}$ Genotype interaction were also significant $(p s<.05)$, owing to a gradual potentiation of locomotor activity with aging in APPxPS1-Ki mice that reached significance at 6 months of age (Table 1c). Refining the analyses to the nocturnal time window revealed stronger differences between groups ( $p<.001$; Table 1d). Indeed, during the night period, APPxPS1-Ki animals were more active than PS1-Ki mice at 4 and 6 months of age.

In the open-field task, no global effect of the Genotype factor was observed on horizontal activity. However, both Age and the Age $\mathrm{x}$ Genotype interaction were significant $(p s<.05)$. A significant difference between genotypes emerged at the age of 6 months with APPxPS1-Ki mice being hyperactive when compared to PS1 controls. APPXPS1-Ki mice, while displaying enhanced locomotion, showed a concurrent reduced vertical activity (Table 1f.), confirming data obtained from neurological primary screen (decreased number of rearings, see above).

\subsubsection{Reduced anxiety-related behaviors}

To assess anxiety-related behaviors during open field testing, a Center-to-Periphery ratio on exploration times was calculated (the higher the ratio, the more time the animals spent in the anxiogenic central zone). ANOVA indicated an effect of Genotype $(p<.01)$ and a significant Age x Genotype interaction $(p<.001)$. Analysis showed that 6-month old APPxPS1-Ki mice had higher ratios, i.e. developed hypoanxiety, in comparison to age-matched controls (Table 1g). In the elevated plus maze, the ratio of time spent in Open (O) vs. Closed (C) arms also permitted the evaluation of anxiety (the higher the $\mathrm{O} / \mathrm{C}$ ratio, the more time animals spent in the anxiogenic open 
arms). ANOVA on this measure revealed effects of Genotype, Age and a significant Age x Genotype interaction $(p s<.01)$. When compared to PS1-Ki controls, 6-month-old (but not younger) APPxPS1-Ki mice showed increased ratios, i.e. lower anxiety levels, (Fig. 4; Table 1h). APPxPS1-Ki mice concurrently presented increased locomotion in the plus-maze at the age of 6 months (Fig. 4; Table 1g) but there were no correlations between activity levels and hypoanxious traits $(r=0.06 ; n s)$.

\subsection{Cognitive impairments in APPXPS1-Ki mice}

During testing in the water maze, APPxPS1-Ki animals had lower swim speeds than control PS1-Ki mice $(p<.001)$ and also presented abnormally tortuous swim paths with high frequency of curved trajectories. Due to variations in swim speeds between genotypes that may impact performance non-specifically, we calculated an unbiased measure of spatial learning that is the percentage of the path length spent by mice in the target quadrant (Janus et al., 2000) (Fig. 5).

ANOVA showed that the overall performance of mice, in both genotypes, varied across ages $(\mathrm{p}<.001)$. In particular, 2-months-old mice showed reduced learning abilities as compared to older animals (see also Vicens et al., 1999, Vicens et al., 2002 for data showing poor performance in very young naïve BL/6 naïve mice). In spite of low learning proficiency, 2-month old mice from the two genotypes improved their performance across learning sessions (all $p \mathbf{s}<.001$ ). There was neither a Genotype effect nor a significant interaction between Session and Genotype factors. When re-tested at 4 months of age, the mice were able to learn a new platform location with no Genotype effect, but a Session x Genotype interaction $(p<.05)$ reflecting a slight, nonsignificant, decrement in performance of APPxPS1-Ki mice. Both group of mice showed clear progress in their search accuracy with training ( $p<.001$ for PS1-Ki and APPxPS1-Ki mice). At 6 months of age, learning was also evidenced, as reflected in an effect of Session $(p<.001)$ that reached statistical significance for the two groups $(p s<.001)$, but at this age APPxPS1-Ki mice clearly exhibited impaired performance compared to control PS1-Ki animals ( $p<.01$; see Fig. 5).

Memory for the platform location was evaluated during single probe trials (no platform) performed at each time point (2, 4 and 6 months). From visual inspection of occupancy plots (Wolfer et al., 2001), it appeared that spatial bias for the target quadrant was lower in APPxPS1-Ki mice than in PS1-Ki mice. This was particularly 
evident at 6 months of age (Fig. 6B). To compare quantitatively the search accuracy for the platform location in the two genotypes, we also calculated a proximity measure (Gallagher et al., 1993), that is, the mouse-toplatform distance averaged across all sampled points of the swim path. ANOVA on this proximity measure indicated a significant effect of Genotype and an Age x Genotype interaction ( $p \mathrm{~s}<.05$; see Fig. 6A). Post hoc analysis showed that 4- and 6- month old PS1-Ki mice swam in closer vicinity to the platform, indicating better memory proficiency, than age-matched APPXPS1-Ki mice $(p s<.05)$. Comparison of performance at different ages in our longitudinal design indicated that PS1-Ki mice gradually improved their memory abilities between 2 and 6 months of age $(p<.001)$, whereas APPxPS1-Ki mice showed the opposite tendency, i.e. a progressive decline in memory performance $(p<.001$; see Fig. $6 \mathrm{~A})$.

\section{Discussion}

The research effort to fight Alzheimer's disease and to understand its physiopathogeny is largely dependent upon the development of valid animal models. To this extend, the APPXPS1-Ki model is among the rare transgenic mouse lines bearing brain amyloidosis together with neuronal loss, and therefore is of particular interest. The present study was undertaken to extensively characterize the neuropathological alterations and functional impairments in this mouse model.

We found that APPxPS1-Ki mice display a significant thinning of the hippocampal pyramidal cell layer, occurring as early as 6 month of age and that the production of new neurons in the dentate gyrus of these mice is also dramatically reduced. Using in vivo MRI measurements, our study revealed cerebral capillary blood flow reduction in the cortex of 6-month old APPxPS1-Ki mice that is paralleled by neurological impairments and memory deficits strongly evocative of hippocampal dysfunction.

As expected, extracellular $A \beta$ deposits were detected in various brain regions of 6-month old animals. At this early age, we observed in addition a remarkable thinning of the CA1-2 cell layer, evocative of local neuronal loss (Casas et al., 2004). From initial reports it appears that 2-month old APPxPS1-Ki mice do not show significant hippocampal neuronal loss whereas 10-month old transgenics display a severe cell loss in this region (Casas et al., 2004). Combined with our results, these data suggest that APPxPS1-Ki mice undergo an age-related loss of 
neurons in the hippocampus, the onset of which is between 2 and 6 months of age. When evaluating potential neuronal replacement based on new neurons generated in the dentate gyrus, we found that hippocampal cell proliferation was reduced by nearly $40 \%$ in APPxPS1-Ki mice. Moreover, the fewer cells produced also showed impaired neuronal differentiation, as illustrated by the massive ( $>90 \%)$ reduction of the number of DCXexpressing immature neurons in APPxPS1-Ki mice. Interestingly, Li and collaborators (Li et al., 2008) reported that differentiation of newly born cells into mature neurons is also severely compromised in AD patients, resulting into a dramatic decrease of hippocampal neurogenesis. The mechanisms leading to hippocampal neuronal loss and decreased neurogenic production in APPXPS1-Ki mice remain hypothetical. Despite parenchymal accumulation of $\mathrm{A} \beta$, there were no correlations between hippocampal amyloid loads and neuronal loss (see also Casas et al., 2004, Schmitz et al., 2004 for similar conclusions) or density of new neurons. It is possible that other $\mathrm{A} \beta$ conformations or localizations may have a higher pathogenic potential. $\mathrm{A} \beta 42$ is a prevalent A $\beta$ species in APPxPS1-Ki mice brain tissue (see biochemical results and also Casas et al., 2004) and is considered to be a very toxic species closely associated with neuronal injury (Walsh and Selkoe, 2007). Also, and more importantly, intracellular A $\beta$ accumulation has been reported in the APPxPS1-Ki line starting at the age of two months in the CA1-2 hippocampal region (Casas et al., 2004). Although still debated, the exquisite pathogenicity of intracellular A $\beta$ is repeatedly reported (Laferla et al., 2007, Wirths and Bayer, 2008a). In particular, intracellular $A \beta$ is mostly detected in brain regions that show subsequent neuronal loss (Christensen et al., 2008a, Oakley et al., 2006). Abnormally up-regulated proteins involved in apoptosis and cell survival have recently been identified in APPxPS1-Ki mice (Damjanac et al., 2007, Page et al., 2006) and this up-regulation may result from intracellular accumulation of $A \beta$. Concerning the observed decreased neurogenic production, it is also possible that highly vulnerable neuronal populations, like new immature neurons, display an increased sensitivity to the toxic effects of $A \beta$. This would account for the near complete absence of hippocampal neurogenesis observed in 6-month old APPxPS1-Ki mice. To date, our report is the first to reveal such a massive reduction of hippocampal adult neurogenesis in transgenic animals modeling AD brain amyloidosis (Verret et al., 2007). Whether abolished hippocampal neurogenesis is linked to CA1-2 cell loss and/or to the impaired hippocampal plasticity previously described in APPxPS1-Ki mice (Bayer et al., 2008) remains to be determined. 
In addition to hippocampal pathology, we showed reduced blood perfusion in the cortex of APPxPS1-Ki mice. Cerebral hypoperfusion has also been reported in $\mathrm{AD}$ patients with the same arterial spin labeling MRI methods as used here (Asllani et al., 2008, Johnson et al., 2005), suggesting that the in vivo measure of perfusion in transgenic mice is a translational marker of the pathology. Interestingly, hypoperfusion in APPxPS1-Ki mice was not detected in subcortical nuclei (thalamus), generally considered to be less affected by AD pathology. As suggested by its restricted topography, decreased blood perfusion may promote or reflect local brain dysfunction and behavioral impairments in APPXPS1-Ki mice. Cortical hypoperfusion has previously been reported in other transgenic lines (Niwa et al., 2002), however the mechanisms responsible for decreased blood flow, in the absence of robust amyloid angiopathy as in the case of the APPXPS1-Ki mice, remain elusive. Cerebral hypoperfusion might be the consequence of the presence of soluble $\mathrm{A} \beta$ as recently shown (Luo et al., 2008). Decreased cortical perfusion might also result from local cortical cell loss and/or abnormal neuronal activity. Indeed, recent observations underlined that a loss of neurons can be detected in isocortical regions (frontal cortex) of 6-month old APPxPS1-Ki mice (Christensen et al., 2008b). Also, neural network dysfunctions involving aberrant GABAergic inhibition of local circuitries have recently been demonstrated in the brain of hAPP mice carrying AD mutations (Palop et al., 2007). In the future, it would be interesting to examine whether cortical blood hypoperfusion in APPxPS1-Ki mice originates from cell loss and/or neuronal dysfunction and whether it is related to behavioral and cognitive defects.

Finally, we demonstrated that APPxPS1-Ki mice display neurological and cognitive symptoms often seen in AD patients and sometimes described in transgenic mouse models (Janus and Westaway, 2001, Pietropaolo et al., 2008). Extending previous findings in APPxPS1-Ki mice (Bayer and Wirths, 2008, Wirths and Bayer, 2008b, Wirths et al., 2007), we reported several abnormal early onset behavioral traits such as decreased motor strength, reduced vertical activity, and altered swimming behaviors. Interestingly, motor symptoms, although modest, have also been depicted in demented patients (see Wirths and Bayer, 2008a for discussion). In APPxPS1-Ki mice, these symptoms are presumably associated with peripheral axonopathy (Bayer and Wirths, 2008, Wirths and Bayer, 2008b, Wirths et al., 2006). More importantly, we further described new phenotypic traits of APPxPS1-Ki mice including: (1) a robust hyperlocomotor behavior that was confirmed using three different tests 
(openfield, actimetry and elevated-plus maze), and (2) abnormal anxiety-related behaviors together with signs of disinhibition that are also symptoms developed by AD patients (Cummings, 1997). Lastly, at the cognitive level, APPXPS1-Ki mice exhibited deficits of acquisition and retention of fine allocentric spatial information. These latter symptoms, not previously described, are fully evocative of spatial disorganization and medial temporal lobe impairment as seen in AD patients. Their onset at 6 months of age in APP/PS1-Ki mice coincides with severe hippocampal pathology (see above).

In summary, APPxPS1-Ki mice develop early neurological deficits and signs of hippocampal dysfunction. At 6 months of age, they display a neuronal loss and an abolished hippocampal neurogenesis, in addition to brain amyloidosis. Brain functional anomalies in this model appear to extend beyond the hippocampus as evidenced by altered isocortical blood perfusion. Further work is needed to explore the exact relationships between $\mathrm{A} \beta$ accumulation, altered neuronal densities, impaired adult neurogenesis, reduced brain perfusion, and associated cognitive deficits. To date, no mouse model exhibits every neuropathological feature of Alzheimer's disease. Therefore, APPxPS1-Ki mice that display concomitant appearance of behavioral, cellular, and pathological markers reminiscent of Alzheimer's disease may represent a valuable tool to evaluate therapies against AD in preclinical research. 
Acknowledgements: We thank the Sanofi-Aventis Neurodegenerative Disease Group for the generous gift of the animals involved in this study. This work was supported by the Del Duca Foundation (BD), the ACI Neurosciences program (MD \& BD) and the ANR Young Researcher program (CR, LV, BD). BD also received funding from Sanofi-Aventis through an academic-industrial partnership. We are grateful to M. Guégan for helpful assistance in histological studies and to Dr. Bruce Brown for his help with the English text.

Disclosure statement: B. Delatour received funding from Sanofi-Aventis between 2005 and 2007 to carry out this research (salary for post-doctoral fellowships). The authors are not aware of any biases that might be perceived as affecting the objectivity of the present research work.

All experiments were conducted in accordance with the ethical standards from French and European laws (European Communities Council Directive of 24 November 1986). The supervisor of the present study (B. Delatour) had received official agreements from the French Ministry of Agriculture to carry out research and experiments on animals (authorization No. 91-282). Experiments were performed in compliance and following approval of the Sanofi-Aventis Animal Care and Use Committee. 


\section{Figure legends}

Figure 1. Neuropathological profile of 6-month old APPxPS1-Ki mice (1/2).

A, B. APPxPS1-Ki develop brain amyloidosis as evidenced by numerous, small-sized, Congo red positive plaques in the parenchyma (B is a magnification of the dorsal hippocampus as outlined in A).

C, D. From Nissl-stained sections (photos taken at the level of dorsal hippocampi as in B), it appears that 6month old APPxPS1-Ki mice might already undergo neuronal loss in the CA1 field as this cell layer shows reduced thickness (C: PS1-Ki mouse; D: APPxPS1-Ki mouse).

E. Regional amyloid loads (mean $\pm \mathrm{SEM}$ ) were calculated from Congo red stained tissue sections in different brain regions (Hipp: entire hippocampus; Hipp (dors): dorsal part of the hippocampus; Cortex: entire cortical mantle; Cortex (PFC): prefrontal cortex). Note that the relative volume occupied by amyloid plaques is greater in the isocortex (prefrontal cortex) than in the hippocampal archicortex.

F. Measurement of the CA1 thickness (individual plots; horizontal bar represents population mean) indicates a $20 \%$ atrophy of this hippocampal cell layer in APPxPS1-Ki as compared to PS1-Ki mice.

Scale bars: $100 \mu \mathrm{m}$ (except A: $1000 \mu \mathrm{m})$. All microphotographs are representative of each genotype. Quantification of amyloid loads and of CA1 thickness was performed in 30 PS1-Ki mice and in 28 APPXPS1-Ki mice.

Figure 2. Neuropathological profile of 6-month old APPxPS1-Ki mice (2/2).

A-D. Hippocampal neurogenesis is severely compromised in APPxPS1-Ki mice at the age of 6-months.

APPxPS1-Ki mice show a deficit in cell proliferation (Ki67 immunostaining; A: PS1-Ki mouse; B: APPxPS1-Ki mouse). Moreover, DCX immunoreactivity, strongly present in the dentate subgranular zone of PS1-Ki mice (C), is almost eradicated in APPxPS1-Ki mice (D), pointing to a massive defect of young hippocampal neurons. Insets in figures A-D illustrate magnified views of DCX and Ki67 positive cells.

E. Absolute numbers of DCX+ immature new neurons in the dentate gyrus (individual plots; horizontal bar represents population mean) is almost abolished in APPxPS1-Ki (90\% reduction). 
F. Blood perfusion, as measured by in vivo MRI methods, is decreased in the posterior cortex of APPxPS1-Ki mice (individual plots; horizontal bar represents population mean), underlining that brain dysfunction in this mouse line extends beyond the hippocampus.

Scale bars: $100 \mu \mathrm{m}$. All microphotographs are representative of each genotype. The number of neuropathologically-assessed mice are: Ki67 immunostainings (PS1-Ki=6; APPxPS1-Ki: 5); DCX immunostaings (PS1-Ki=15; APPxPS1-Ki: 14)

Table 1. APPxPS1-Ki mice demonstrate various and gradual neurological impairments.

Mice were evaluated at different ages in a neurological battery. Primary screening allowed the measurement of vertical activity (a). Motor strength was assessed using the wire grid test (b). During actimetry (c, d) and open field $(e, f)$ tests, various aspects of locomotor behavior were measured. Anxiety-related behaviors were quantified in the open field $(\mathrm{g})$ and elevated plus-maze $(\mathrm{h}, \mathrm{i})$ tests.

For each test, the measured dependent variables are represented as mean $\pm \mathrm{SEM}$. Effects of the Age factor are symbolized for each genotype by upward / downward arrows $(p<.05)$. Effects of the Genotype factor are also illustrated, by white and black squares, at each age (see caption).

APPxPS1-Ki mice show various abnormal neurological traits, with variable onset and progression. Major neurological impairments involve: motor defects (loss of motor strength and of vertical activity), increased locomotor activity, and decreased anxiety-related behaviors.

Figure 3. APPxPS1-Ki mice develop locomotor hyperactivity with aging.

Locomotion was assessed during 24 hours at 2 (A), 4 (B) and 6 (C) months of age. The graphs illustrate the mean distance traveled every 30 minutes. At each age, both genotypes show gradual habituation (decreased activity) after placement in the new environment. A renewal of activity is observed, as expected, during the night period but is stronger in APPxPS1-Ki mice as compared to PS1-Ki controls. The nocturnal increase in locomotion of APPxPS1-Ki mice is gradually potentiated with aging, indicating an age-related worsening of hyperactivity in this genotype. 
Figure 4. APPxPS1-Ki show abnormally low levels of anxiety.

At the age of 6-months, APPxPS1-Ki mice show evidence of disinhibition in the elevated plus maze task with increased intrusions and time spent in the anxiogenic open arms of the maze (vertical arms in the illustration; the figure depicts activity plots of two representative mice). This trait is not the result of overall hyperactivity in APPxPS1-Ki mice as, in this genotype, there is no correlation between locomotor activity in the maze and time spent in the open arms.

Figure 5. APPxPS1-Ki mice develop a gradual impairment in the acquisition of spatial information.

Spatial reference memory in the water maze task was evaluated in 2-, 4- and 6-month old mice using an unbiased measure ( $\%$ of distances traveled in the target quadrant: mean \pm SEM). At 2 months of age, both genotypes demonstrate difficulties in learning the task although their performances improve across training sessions. Acquisition proficiency largely increases when the mice are re-tested two months later and, at that age, no differences are observed between the two genotypes. Finally, at 6 months of age, a clear learning deficit is observed in APPxPS1-Ki mice $(p<.01)$.

Figure 6. APPxPS1-Ki mice develop a gradual impairment in the retention of spatial information.

From the age of 4 months, APPxPS1-Ki mice display spatial memory impairments in the water maze task. A. During probe tests, APPxPS1-Ki mice navigate at larger distance (mean $\pm \mathrm{SEM}$ ) from the spatial goal location (platform position) than do PS1-Ki control mice. The lack of finely-tuned spatial representations in APPxPS1-Ki mice was observed at 4 and 6 months of age, but not in younger mice. B. Reduced spatial bias in APPxPS1-Ki mice was also directly evidenced by their occupancy plots (here illustrated in 6-month old animals) that show a less narrowed exploration pattern. To build the occupancy plots, the surface of the maze was divided in small tiles of equal sizes and the time spent in each tiles was color-coded according to its value (lookup table with white, yellow and red colors corresponding respectively to low, medium and high durations; the occupancy plots represent data cumulated and averaged for each genotype). 


\section{References}

Asllani, I., Habeck, C., Scarmeas, N., Borogovac, A., Brown, T.R., Stern, Y., 2008. Multivariate and univariate analysis of continuous arterial spin labeling perfusion MRI in Alzheimer's disease, J. Cereb. Blood Flow Metab. 28(4), 725-736.

Bayer, T.A., Breyhan, H., Duan, K., Rettig, J., Wirths, O., 2008. Intraneuronal beta-amyloid is a major risk factor-novel evidence from the APP/PS1KI mouse model, Neurodegener. Dis. 5(3-4), 140-142.

Bayer, T.A., Wirths, O., 2008. Review on the APP/PS1KI mouse model: intraneuronal Abeta accumulation triggers axonopathy, neuron loss and working memory impairment, Genes Brain Behav. 7 Suppl 1, 6-11.

Blanchard, V., Moussaoui, S., Czech, C., Touchet, N., Bonici, B., Planche, M., Canton, T., Jedidi, I., Gohin, M., Wirths, O., Bayer, T.A., Langui, D., Duyckaerts, C., Tremp, G., Pradier, L., 2003. Time sequence of maturation of dystrophic neurites associated with Abeta deposits in APP/PS1 transgenic mice, Exp. Neurol. 184(1), 247-263.

Burguiere, E., Arleo, A., Hojjati, M.R., Elgersma, Y., Zeeuw, C.I., Berthoz, A., Rondi-Reig, L., 2005. Spatial navigation impairment in mice lacking cerebellar LTD: a motor adaptation deficit?, Nat. Neurosci. 8(10), 12921294.

Calhoun, M.E., Wiederhold, K.H., Abramowski, D., Phinney, A.L., Probst, A., Sturchler-Pierrat, C., Staufenbiel, M., Sommer, B., Jucker, M., 1998. Neuron loss in APP transgenic mice, Nature 395(6704), 755-756.

Casas, C., Sergeant, N., Itier, J.M., Blanchard, V., Wirths, O., van der Kolk, N., Vingtdeux, V., van de Steeg, E., Ret, G., Canton, T., Drobecq, H., Clark, A., Bonici, B., Delacourte, A., Benavides, J., Schmitz, C., Tremp, G., Bayer, T.A., Benoit, P., Pradier, L., 2004. Massive CA1/2 neuronal loss with intraneuronal and N-terminal truncated Abeta42 accumulation in a novel Alzheimer transgenic model, Am. J. Pathol. 165(4), 1289-1300.

Christensen, D.Z., Bayer, T.A., Wirths, O., 2008a. Intracellular Abeta triggers neuron loss in the cholinergic system of the APP/PS1KI mouse model of Alzheimer's disease, Neurobiol. Aging.

Christensen, D.Z., Kraus, S.L., Flohr, A., Cotel, M.C., Wirths, O., Bayer, T.A., 2008b. Transient intraneuronal Abeta rather than extracellular plaque pathology correlates with neuron loss in the frontal cortex of APP/PS1KI mice, Acta Neuropathol 116(6), 647-655.

Cotel, M.C., Bayer, T.A., Wirths, O., 2008. Age-dependent loss of dentate gyrus granule cells in APP/PS1KI mice, Brain Res. 1222, 207-213. 
Cummings, J.L., 1997. The Neuropsychiatric Inventory: assessing psychopathology in dementia patients, Neurology 48(5 Suppl 6), S10-16.

Damjanac, M., Rioux Bilan, A., Paccalin, M., Pontcharraud, R., Fauconneau, B., Hugon, J., Page, G., 2007. Dissociation of Akt/PKB and ribosomal S6 kinase signaling markers in a transgenic mouse model of Alzheimer's disease, Neurobiol. Dis. 29(2), 354-367.

Gallagher, M., Burwell, R., Burchinal, M., 1993. Severity of spatial learning impairment in aging: development of a learning index for performance in the Morris water maze, Behav. Neurosci. 107(4), 618-626.

Hardy, J.A., Higgins, G.A., 1992. Alzheimer's disease: the amyloid cascade hypothesis, Science 256(5054), 184-185. Irizarry, M.C., Soriano, F., McNamara, M., Page, K.J., Schenk, D., Games, D., Hyman, B.T., 1997. Abeta deposition is associated with neuropil changes, but not with overt neuronal loss in the human amyloid precursor protein V717F (PDAPP) transgenic mouse, J. Neurosci. 17(18), 7053-7059.

Janus, C., D'Amelio, S., Amitay, O., Chishti, M.A., Strome, R., Fraser, P., Carlson, G.A., Roder, J.C., St GeorgeHyslop, P., Westaway, D., 2000. Spatial learning in transgenic mice expressing human presenilin 1 (PS1) transgenes, Neurobiol. Aging 21(4), 541-549.

Janus, C., Westaway, D., 2001. Transgenic mouse models of Alzheimer's disease, Physiol. Behav. 73(5), 873-886. Johnson, N.A., Jahng, G.H., Weiner, M.W., Miller, B.L., Chui, H.C., Jagust, W.J., Gorno-Tempini, M.L., Schuff, N., 2005. Pattern of cerebral hypoperfusion in Alzheimer disease and mild cognitive impairment measured with arterial spin-labeling MR imaging: initial experience, Radiology 234(3), 851-859.

Kober, F., Duhamel, G., Cozzone, P.J., 2008. Experimental comparison of four FAIR arterial spin labeling techniques for quantification of mouse cerebral blood flow at 4.7 T, NMR Biomed. 21(8), 781-792.

Laferla, F.M., Green, K.N., Oddo, S., 2007. Intracellular amyloid-beta in Alzheimer's disease, Nat. Rev. Neurosci. 8(7), 499-509.

Le Cudennec, C., Faure, A., Ly, M., Delatour, B., 2008. One-year longitudinal evaluation of sensori-motor functions in APP751SL transgenic mice, Genes Brain Behav. 7(Suppl. 1), 83-92.

Li, B., Yamamori, H., Tatebayashi, Y., Shafit-Zagardo, B., Tanimukai, H., Chen, S., Iqbal, K., Grundke-Iqbal, I., 2008. Failure of neuronal maturation in Alzheimer disease dentate gyrus, J. Neuropathol. Exp. Neurol. 67(1), 7884. 
Luo, F., Seifert, T.R., Edalji, R., Loebbert, R.W., Hradil, V.P., Harlan, J., Schmidt, M., Nimmrich, V., Cox, B.F., Fox, G.B., 2008. Non-invasive characterization of beta-amyloid(1-40) vasoactivity by functional magnetic resonance imaging in mice, Neuroscience 155(1), 263-269.

Niwa, K., Kazama, K., Younkin, S.G., Carlson, G.A., Iadecola, C., 2002. Alterations in cerebral blood flow and glucose utilization in mice overexpressing the amyloid precursor protein, Neurobiol. Dis. 9(1), 61-68.

Oakley, H., Cole, S.L., Logan, S., Maus, E., Shao, P., Craft, J., Guillozet-Bongaarts, A., Ohno, M., Disterhoft, J., Van Eldik, L., Berry, R., Vassar, R., 2006. Intraneuronal beta-amyloid aggregates, neurodegeneration, and neuron loss in transgenic mice with five familial Alzheimer's disease mutations: potential factors in amyloid plaque formation, J. Neurosci. 26(40), 10129-10140.

Page, G., Rioux Bilan, A., Ingrand, S., Lafay-Chebassier, C., Pain, S., Perault Pochat, M.C., Bouras, C., Bayer, T., Hugon, J., 2006. Activated double-stranded RNA-dependent protein kinase and neuronal death in models of Alzheimer's disease, Neuroscience 139(4), 1343-1354.

Palop, J.J., Chin, J., Roberson, E.D., Wang, J., Thwin, M.T., Bien-Ly, N., Yoo, J., Ho, K.O., Yu, G.Q., Kreitzer, A., Finkbeiner, S., Noebels, J.L., Mucke, L., 2007. Aberrant excitatory neuronal activity and compensatory remodeling of inhibitory hippocampal circuits in mouse models of Alzheimer's disease, Neuron 55(5), 697-711.

Paxinos, G., Franklin, K.B.J., 2001. The mouse brain in stereotaxic coordinates, second ed., Academic Press, San Diego.

Pietropaolo, S., Feldon, J., Yee, B.K., 2008. Age-dependent phenotypic characteristics of a triple transgenic mouse model of Alzheimer disease, Behav. Neurosci. 122(4), 733-747.

Rogers, D.C., Fisher, E.M., Brown, S.D., Peters, J., Hunter, A.J., Martin, J.E., 1997. Behavioral and functional analysis of mouse phenotype: SHIRPA, a proposed protocol for comprehensive phenotype assessment, Mamm. Genome 8(10), 711-713.

Scher, A.I., Xu, Y., Korf, E.S., White, L.R., Scheltens, P., Toga, A.W., Thompson, P.M., Hartley, S.W., Witter, M.P., Valentino, D.J., Launer, L.J., 2007. Hippocampal shape analysis in Alzheimer's disease: A population-based study, Neuroimage 36(1), 8-18.

Schmitz, C., Rutten, B.P., Pielen, A., Schafer, S., Wirths, O., Tremp, G., Czech, C., Blanchard, V., Multhaup, G., Rezaie, P., Korr, H., Steinbusch, H.W., Pradier, L., Bayer, T.A., 2004. Hippocampal neuron loss exceeds amyloid plaque load in a transgenic mouse model of Alzheimer's disease, Am. J. Pathol. 164(4), 1495-1502. 
Sun, Y., Schmidt, N.O., Schmidt, K., Doshi, S., Rubin, J.B., Mulkern, R.V., Carroll, R., Ziu, M., Erkmen, K., Poussaint, T.Y., Black, P., Albert, M., Burstein, D., Kieran, M.W., 2004. Perfusion MRI of U87 brain tumors in a mouse model, Magn. Reson. Med. 51(5), 893-899.

Takeuchi, A., Irizarry, M.C., Duff, K., Saido, T.C., Hsiao Ashe, K., Hasegawa, M., Mann, D.M., Hyman, B.T., Iwatsubo, T., 2000. Age-related amyloid beta deposition in transgenic mice overexpressing both Alzheimer mutant presenilin 1 and amyloid beta precursor protein Swedish mutant is not associated with global neuronal loss, Am. J. Pathol. 157(1), 331-339.

Urbanc, B., Cruz, L., Le, R., Sanders, J., Ashe, K.H., Duff, K., Stanley, H.E., Irizarry, M.C., Hyman, B.T., 2002. Neurotoxic effects of thioflavin S-positive amyloid deposits in transgenic mice and Alzheimer's disease, Proc. Natl. Acad. Sci. U. S. A. 99(22), 13990-13995.

Verret, L., Jankowsky, J.L., Xu, G.M., Borchelt, D.R., Rampon, C., 2007. Alzheimer's-type amyloidosis in transgenic mice impairs survival of newborn neurons derived from adult hippocampal neurogenesis, J. Neurosci. 27(25), 6771-6780.

Vicens, P., Bernal, M.C., Carrasco, M.C., Redolat, R., 1999. Previous training in the water maze: differential effects in NMRI and C57BL mice, Physiol. Behav. 67(2), 197-203.

Vicens, P., Redolat, R., Carrasco, M.C., 2002. Effects of early spatial training on water maze performance: a longitudinal study in mice, Exp. Gerontol. 37(4), 575-581.

Walsh, D.M., Selkoe, D.J., 2007. Abeta Oligomers - a decade of discovery, J. Neurochem. 101(5), 1172-1184.

West, M.J., Kawas, C.H., Martin, L.J., Troncoso, J.C., 2000. The CA1 region of the human hippocampus is a hot spot in Alzheimer's disease, Ann. N. Y. Acad. Sci. 908, 255-259.

Williams, D.S., Detre, J.A., Leigh, J.S., Koretsky, A.P., 1992. Magnetic-resonance-imaging of perfusion using spin inversion of arterial water, Proc. Natl. Acad. Sci. U. S. A. 89(1), 212-216.

Wirths, O., Bayer, T., 2008a. Early Intraneuronal $\beta$-Amyloid Pathology: Do Transgenic Mice Represent Valid Model Systems?, The Open Aging Journal 2, 7-12.

Wirths, O., Bayer, T.A., 2008b. Motor impairment in Alzheimer's disease and transgenic Alzheimer's disease mouse models, Genes Brain Behav. 7 Suppl 1, 1-5.

Wirths, O., Breyhan, H., Schafer, S., Roth, C., Bayer, T.A., 2007. Deficits in working memory and motor performance in the APP/PS1ki mouse model for Alzheimer's disease, Neurobiol. Aging 29(6), 891-901. 
Wirths, O., Weis, J., Kayed, R., Saido, T.C., Bayer, T.A., 2006. Age-dependent axonal degeneration in an Alzheimer mouse model, Neurobiol. Aging 28(11), 1689-1699.

Wolfer, D.P., Madani, R., Valenti, P., Lipp, H.P., 2001. Extended analysis of path data from mutant mice using the public domain software Wintrack, Physiol. Behav. 73(5), 745-753. 
a. Primary screen - Vertical activity (nb rearings)

\begin{tabular}{llll|rlll}
\hline 2 months & 16,0 & \pm & 1,7 & 13,2 & \pm & 2,5 & $\square$ \\
4 months & 12,2 & \pm & 2,4 & 4,4 & \pm & 1,3 & $\mathbf{q}$ \\
6 months & 18,1 & \pm & 2,8 & 2,9 & \pm & 1,1 & $\square$ \\
Age effect & & - & & & $\searrow$ & & \\
\hline
\end{tabular}

b. Wire grid test - latency to fall (s)

\begin{tabular}{llll|rccc}
\hline 2 months & 56,9 & \pm & 3,1 & 53,4 & \pm & 3,7 & $\square$ \\
4 months & 60,0 & \pm &, \pm 0 & 33,0 & \pm & 6,6 & $\square \square$ \\
6 months & 56,3 & \pm &, \pm 7 & 7,1 & \pm & 1,4 & $\square$ \\
Age effect & & - & & & $\searrow$ &
\end{tabular}

c. 24 hrs actimetry test - locomotion (m)

\begin{tabular}{llll|rlll}
\hline 2 months & 682,0 & \pm & 45,0 & 816,2 & \pm & 73,0 & $\square$ \\
4 months & 862,1 & \pm & $\pm 9,5$ & 1057,5 & \pm & 96,2 & $\square$ \\
6 months & 718,4 & \pm & 95,8 & 1253,0 & \pm & 99,0 & $\square$ \\
\hline Age effect & & - & & & $\boldsymbol{\pi}$ & & \\
\hline
\end{tabular}

d. 24 hrs actimetry test - locomotion, night period (m)

\begin{tabular}{llll|llll}
\hline 2 months & 338,8 & \pm & 49,3 & 492,2 & \pm & 56,7 & $\square$ \\
4 months & 568,9 & \pm & 68,1 & 828,1 & \pm & 93,0 & $\square$ \\
6 months & 466,7 & \pm & 69,5 & 868,0 & \pm & 76,4 & $\square$ \\
Age effect & & $\pi$ & & & $\pi$ & & \\
\hline
\end{tabular}

e. Open-field test - horizontal activity $(m)$

\begin{tabular}{llll|llll}
\hline 2 months & 52,3 & $\pm 3,0$ & 51,4 & \pm & 4,2 & $\square$ \\
4 months & 39,8 & $\pm 3,2$ & 45,8 & $\pm 4,9$ & $\square$ \\
6 months & 38,5 & $\pm 2,9$ & 53,4 & \pm & 5,5 & $\square$ \\
Age effect & & $\searrow$ & & - & & \\
\hline
\end{tabular}

\section{f. Open-field test - Vertical activity (nb rearings)}

\begin{tabular}{lrrr|rlll}
\hline 2 months & 34,9 & \pm & 6,0 & 25,9 & \pm & 4,0 & $\square$ \\
4 months & 33,4 & \pm & 5,5 & 10,7 & \pm & 2,4 & $\mathbf{q}$ \\
6 months & 14,2 & \pm & 3,2 & 2,3 & \pm & 0,6 & $\mathbf{\square}$ \\
Age effect & & $\boldsymbol{y}$ & & $\boldsymbol{y}$ & & \\
\hline
\end{tabular}

\section{g. Open-field test - Ratio Center/Periphery}

\begin{tabular}{llll|llll}
\hline 2 months & 0,21 & \pm & 0,5 & 0,17 & \pm & 0,6 & $\square$ \\
4 months & 0,13 & \pm & 1,4 & 0,21 & \pm & 0,8 & $\square$ \\
6 months & 0,09 & \pm & 2,2 & 0,34 & \pm & 0,7 & $\square$ \\
Age effect & & $\searrow$ & & & $\pi$ & & \\
\hline
\end{tabular}

h. Elevated plus maze test - Open/Closed ratio

\begin{tabular}{|c|c|c|c|c|c|c|c|}
\hline 2 months & 0,33 & \pm & 0,06 & 0,51 & \pm & 0,08 & 口 \\
\hline 4 months & 0,09 & \pm & 0,07 & 0,17 & \pm & 0,04 & $\square$ \\
\hline 6 months & 0,03 & \pm & 0,01 & 1,28 & \pm & 0,59 & 口 \\
\hline Age effect & \multicolumn{3}{|c|}{ ע } & \multicolumn{3}{|c|}{$\pi$} & \\
\hline \multicolumn{8}{|c|}{ i. Elevated plus maze test - horizontal activity (m) } \\
\hline 2 months & 9,3 & \pm & 0,6 & 8,8 & \pm & 0,6 & $\square$ \\
\hline 4 months & 4,8 & \pm & 0,8 & 6,9 & \pm & 0,7 & $\square$ \\
\hline 6 months & 3,8 & \pm & 0,5 & 10,6 & \pm & 1,5 & m \\
\hline Age effect & \multicolumn{3}{|c|}{ y } & \multicolumn{3}{|c|}{$\pi$} & \\
\hline
\end{tabular}

Table 1. 


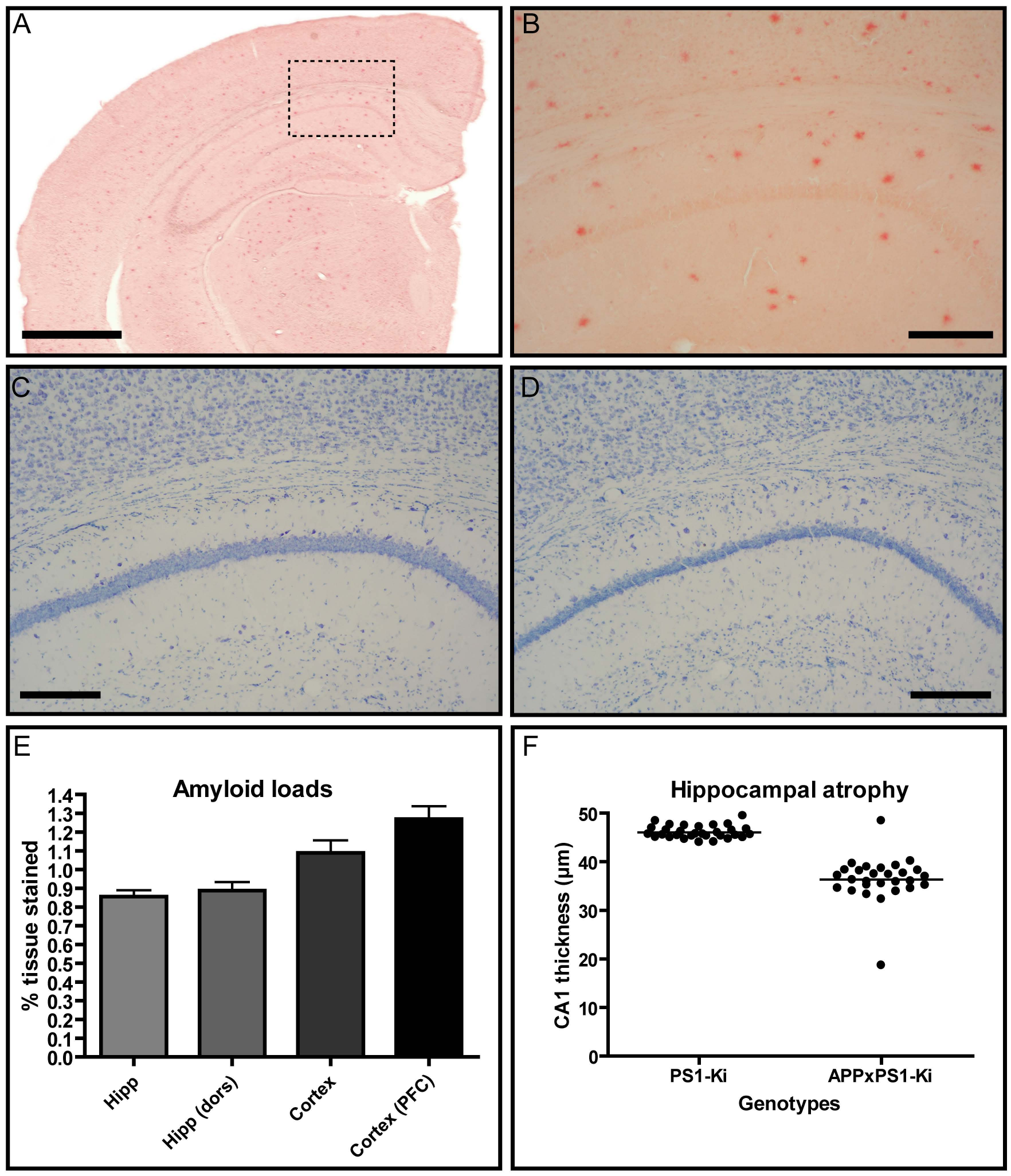

Faure_Figure_1 

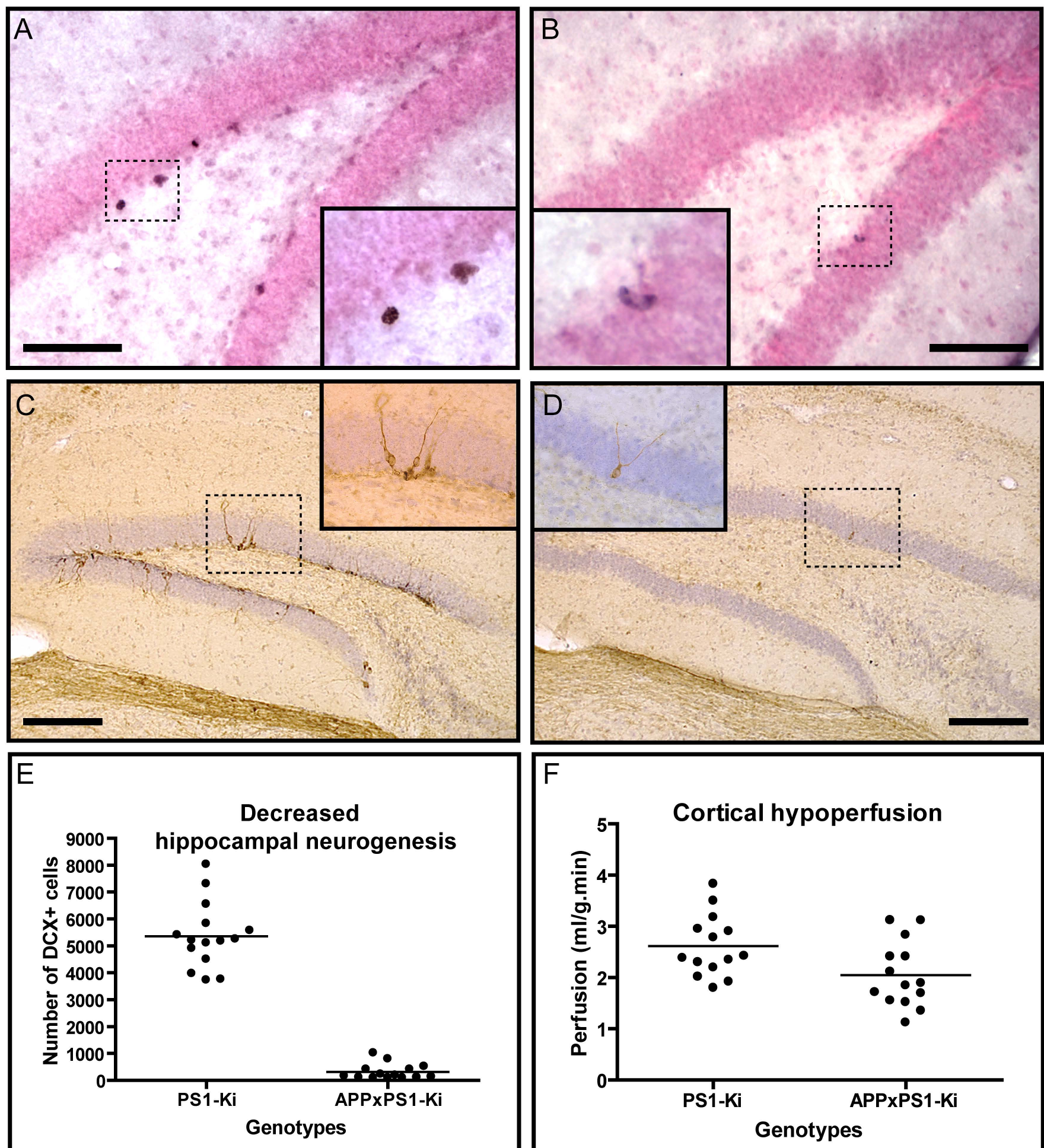

Faure_Figure_2 


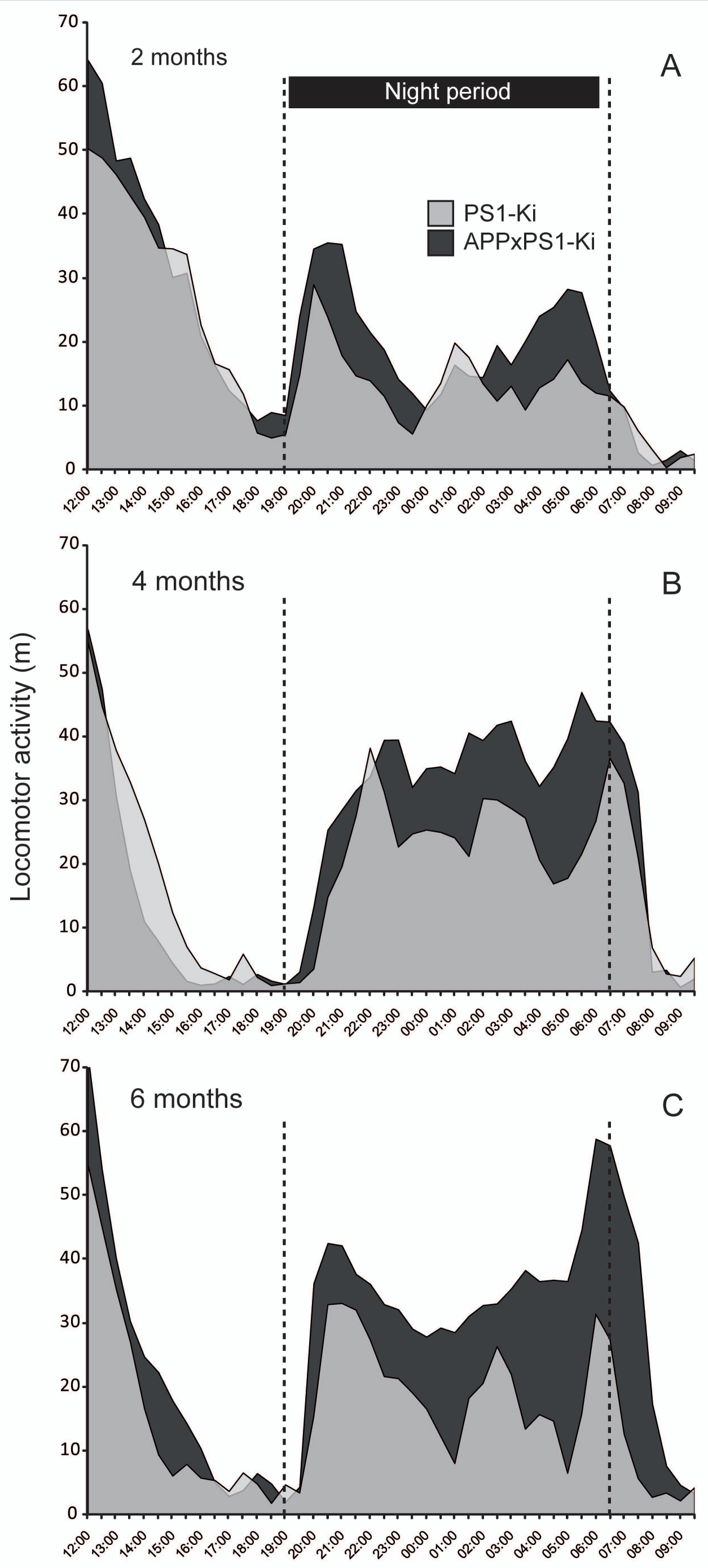

Faure_Figure_3 

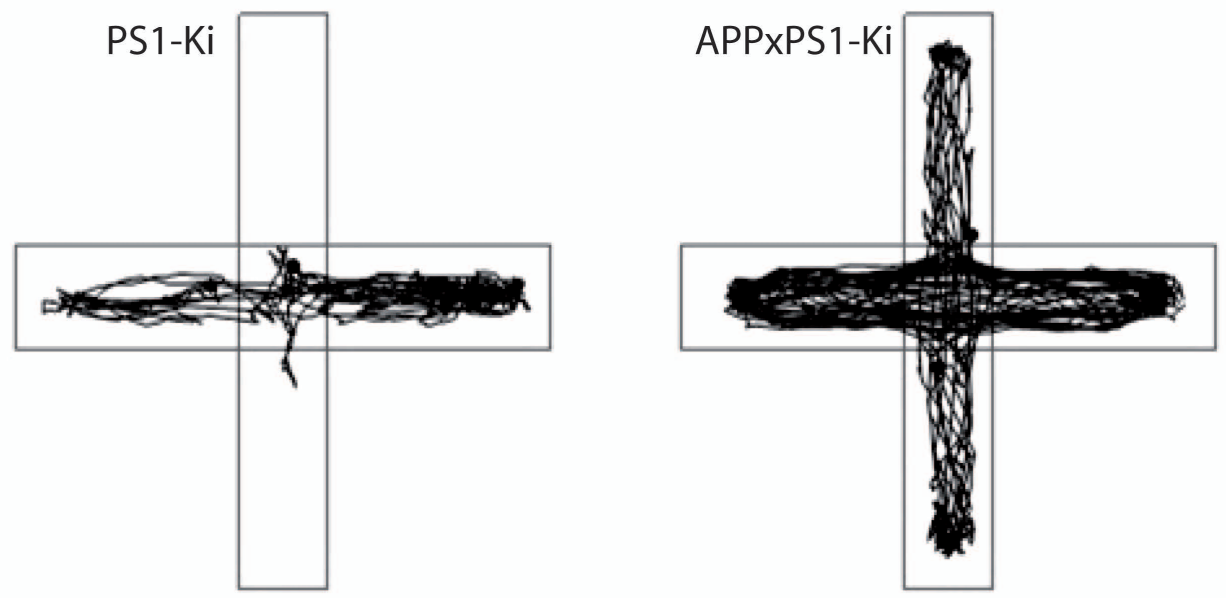

Faure_Figure_4 


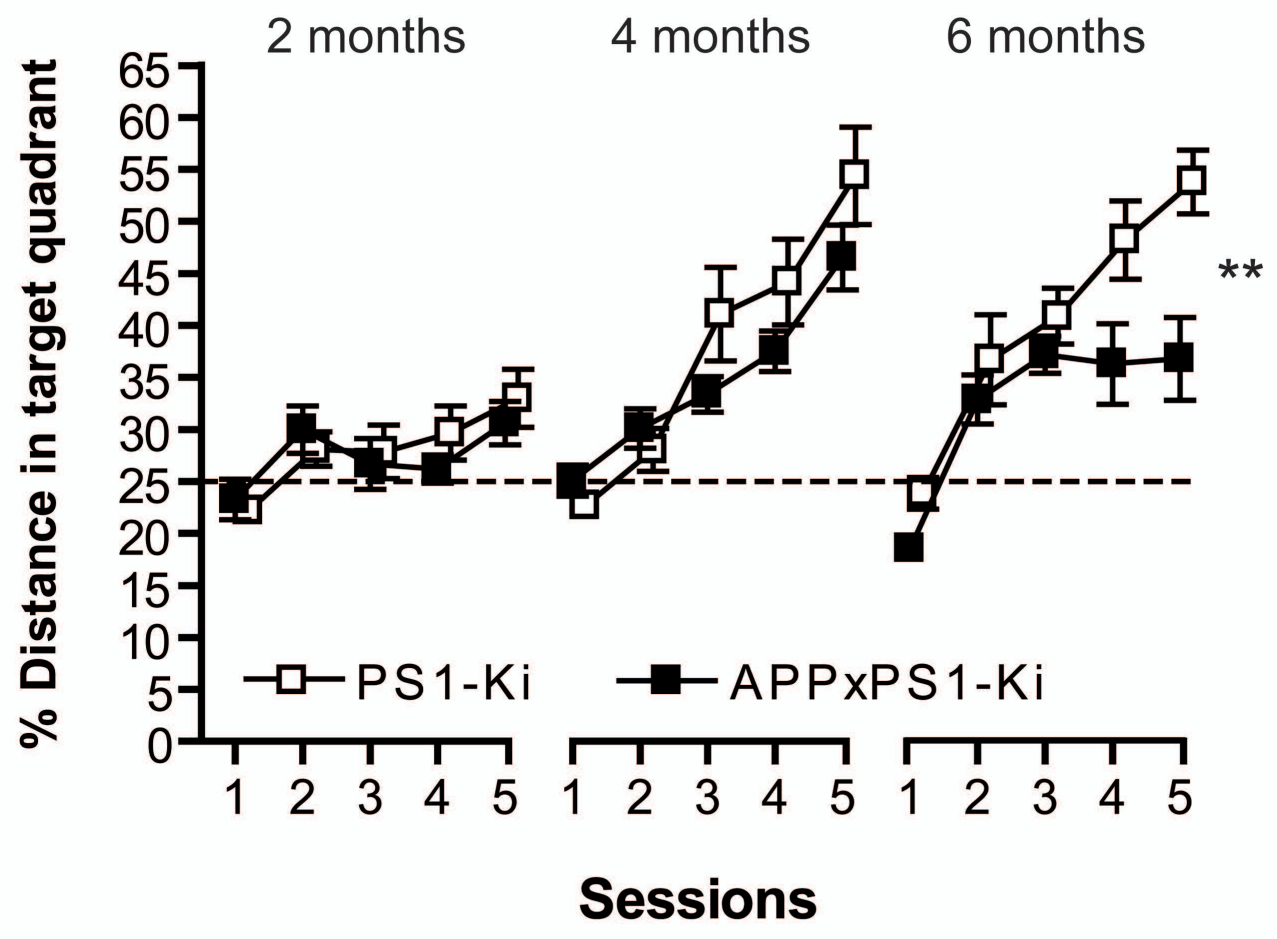

Faure_Figure_5 
A

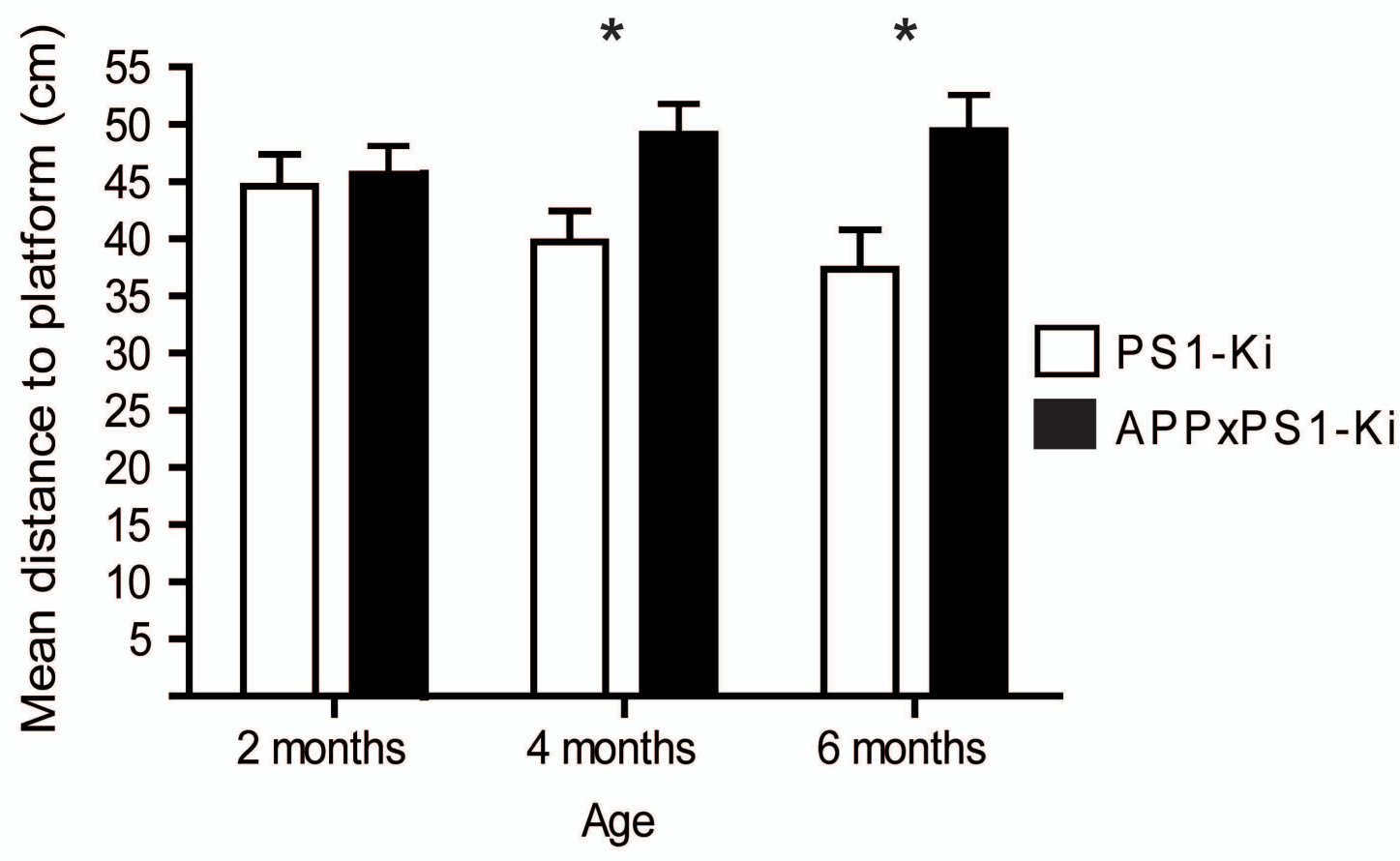

B

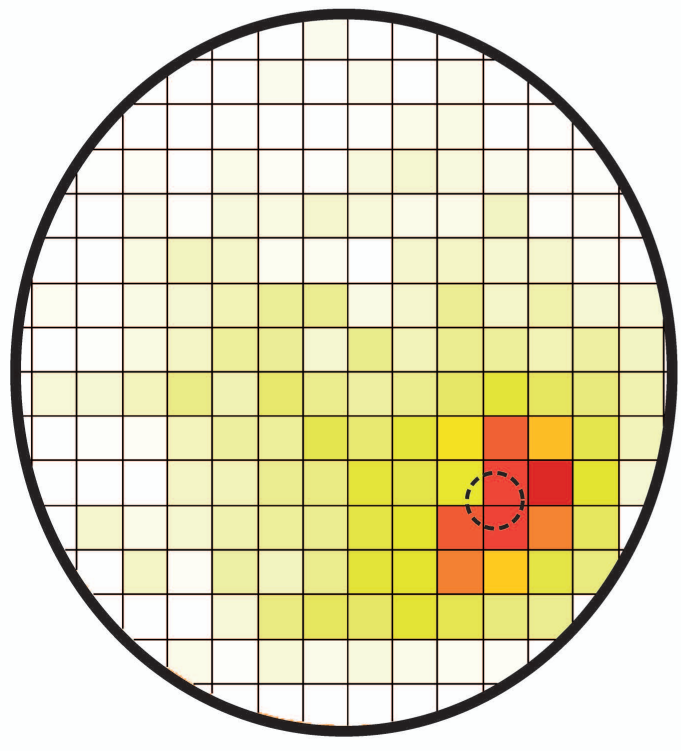

PS1-Ki

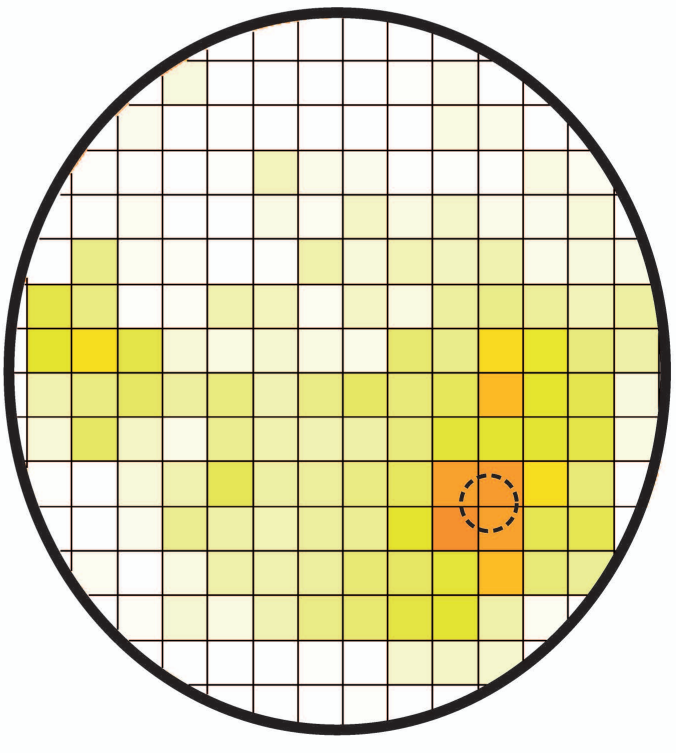

APPxPS1-Ki

Faure_Figure_6 